\title{
6
}

\section{Looking at Ourselves: The Quality of Life of Faculty Development Professionals}

Kathleen T. Brinko, Sally S. Atkins, and Marian E. Miller Appalachian State University

Responses to a questionnaire revealed that faculty development professionals typically juggle several roles- which they find to be energizing - and typically balance multiple challenges and stressors - which they feel they handle well. These faculty developers are enthusiastic about and, in many cases, sustained by their work because they find opportunities for lifelong learning, professional growth, and meaningful work.

\section{INTRODUCTION}

s a profession, we faculty developers know very little about ourselves. The Amajority of the literature in our field addresses our practice, primarily the improvement of teaching. Graf and Wheeler (1996) provided us with some demographic and job-related information, and Lewis (1996) and Tiberius (2002) gave brief histories of the evolution of the practice of faculty development. However, we have no information on how faculty developers perceive their work and professional quality of life.

Over a period of 18 years, the Hubbard Center for Faculty and Staff Support at Appalachian State University has systematically studied the quality of life of several groups, including faculty (Atkins, Brinko, Butts, Claxton, \& Hubbard, 2001; Hageseth \& Atkins, 1988), staff (Hageseth \& Atkins, 1989), new faculty (Branch, 1995), and chairpersons (Atkins \& Hageseth, 1991). The university has also engaged in an ongoing examination of the psychological and philosophical issues underlying faculty and staff well-being (Hubbard 
\& Atkins, 1995; Hubbard, Atkins, \& Brinko, 1998; van der Bogert, Brinko, Atkins, \& Arnold, 1990). These studies, as well as hundreds of formal and informal consultations, have influenced a number of programmatic and structural changes at Appalachian State and have shaped the Hubbard Center's unique holistic approach to faculty development (Hubbard, Atkins, \& Brinko, 1998). With this long-standing interest in studying quality of life issues, and prompted by conversations with colleagues in faculty development who had quality of life issues, we decided to turn our attention to those issues within our own profession.

\section{Changing Contexts, Changing Roles}

It is important to note that this study has taken place amidst tremendous changes occurring in American higher education and in the roles of the faculty development professional within these changing contexts. Changing attitudes regarding the roles of the reacher and the learner, research on the nature of learning from the cognitive sciences, and changes within organizational systems within higher education continue to shape the profession of faculty development (Lieberman \& Guskin, 2003; Tiberius, 2002). From the assumptions of the $1950 \mathrm{~s}$, when professors were seen primarily as masters of the discipline, through the evolution of many faculty development programs and centers of the early 1970 s that focused primarily upon assisting professors in understanding and mastering the complex instructional comperencies of pedagogy, the role and responsibility of the faculty developer changed (Centra, 1976; Gaff, 1975; Lieberman \& Guskin, 2003; Tiberius, 2002). In today's world of higher education, the role of the faculty member has become increasingly complex, as has that of the faculty developer. Shaped by the differing historical contexts and the evolution of attitudes regarding teaching and learning, faculty developers now find themselves needing to embrace multiple roles within the system of the institution (Tiberius, 2002). Increasingly, faculty developers are called upon to address faculty life and career concerns within the personal dimension, such as life stage issues, wellness programs, and retirement issues (Lewis, 1996). More than ever, faculty development professionals are called upon to work as institutional agents of transformational change, helping faculty members to design environments for learning, embracing ideas of learning communities, fostering learning organizations, and navigating faculty development as a dialectic berween individuals and the organizational system (Langley, O'Connor, \& Welkener, 2004; Lieberman \& Guskin, 2003; Senge, 1990). These complex challenges 
of modern faculty development work would seem to have a major impact on faculty developers' perceived quality of life.

\section{METHOD}

Although our previous quality of life studies included in-depth interviews, we believed that this first study of faculty developers should be exploratory and should try to capture a broad overview of their quality of life. These results, then, would shape questions for later in-depth interviews.

In December 2001, we developed a paper-and-pencil questionnaire to mail to directors and assistant or associate directors of faculty development centers. After receiving approval from the university's institutional review board for human subjects research and from the university's statistician concerning coding and analyzing the data, we conducted a pilot study of our questionnaire with five professionals in the field who were no longer working as directors or who did not work in the United States. Based on the feedback from this pilot study we refined the questionnaire, and in February 2002, we mailed a 24-item questionnaire (Appendix 6.1) to 256 directors and a 23-item questionnaire (the same, minus Question 7) to 52 associate or assistant directors of faculty development programs in the United States, as listed in the POD Membership Directory (Professional and Organizational Development Network in Higher Education, 2001).

Each questionnaire was coded with a unique number to track returns and to follow up. However, to protect subject confidentiality, graduate assistants received the completed questionnaires, kept track of returns, and conducted the follow-up mailing. To further protect the subjects, the graduate assistants also entered all quantitative data into a database and keyboarded all handwritten responses to the qualitative questions. In total, we received 145 usable questionnaires (response rate $=57 \%$ ) from the directors surveyed and 36 usable questionnaires (response rate $=69 \%$ ) from the associate or assistant directors surveyed.

Using SPSS, we summarized the quantitative demographic data (Questions 1 through 9) and quality of life data (Questions 10 through 20), performed Pearson product moment correlations, and created scatter plots among possibly related factors (Questions 1, 6, and 10a, 10b, 10c). Using qualitative methods, we coded the open-ended questions (Questions 21 through 24), generating categories from the data. 


\section{Demographics}

\section{Demographics of Directors}

The directors ranged in age from 36 to 71 years, with a mean age of 53 years and a median age of 55 years. Of the respondents, $67 \%$ were female and $33 \%$ were male. The majority of directors $(94 \%)$ held a doctorate; $34 \%$ obtained their highest degree in education, $16 \%$ in the social sciences, and $13 \%$ in the humanities. The remaining $37 \%$ obtained their highest degree in business, science, mathematics, communication, and other disciplines. Respondents earned their highest degree from 0 to 39 years prior to the survey, with the degrees fairly equally distributed over that span of time.

Respondents began as practitioners in faculty development from 0 to 33 years prior to the survey. Those who had worked in the field from 0 to 5 years comprised $39 \%$ of the sample, those who worked 6 to 10 years comprised $22 \%$ of the sample, and those who worked in the field for 11 to 33 years comprised $37 \%$ of the sample. Respondents held the position of director from less than 1 year to 26 years, with an average of 6 years. Interestingly, $60 \%$ of responding directors were relatively new, with 0 to 5 years experience in the job. Only $18 \%$ served previously as assistant or associate director before assuming the position as director, and they had served in that capacity from a few months to 10 years.

Responding directors came from public institutions (65\%), private institutions (30\%), and other kinds of settings $(5 \%)$, such as two-year colleges, medical colleges, and system-wide faculty development offices. With regard to the classification of their institutions, $37 \%$ were directors at research I or II universities, $7 \%$ at doctoral I or II universities, $34 \%$ at comprehensive universities, $12 \%$ at liberal arts colleges, and $4 \%$ at other kinds of settings.

Less than half $(47 \%)$ reported working full-time as director; an additional $14 \%$ reported that they were employed as director three-quarters time, $27 \%$ reported one-half time, and $8 \%$ reported one-third to one-quarter time. Thus, many respondents reported that in addition to their role as director, they held other roles in the institution, such as faculty member (76\%), editor (14\%), assistant or associate dean (3\%), assistant or associate vice provost $(4 \%)$, and other (23\%).

\section{Demographics of Assistant or Associate Directors}

The assistant or associate directors ranged in age from 29 to 68 years, with an average age of 47 years. Of the respondents, $69 \%$ were female and $31 \%$ were male. Most $(75 \%)$ held a doctorate, $47 \%$ held their highest degree in education, $19 \%$ held their highest degree in the humanities, and the remaining $34 \%$ 
held degrees in a variety of disciplines, including science, mathematics, social sciences, or other. Respondents earned their highest degree from 0 to 35 years prior to the survey, with the degrees fairly equally distributed over that span of time.

Assistant or associate directors began as practitioners in faculty development from 0 to 25 years prior to the survey, with their beginning dates fairly equally distributed over that span of time. Respondents served as assistant or associate directors from 1 to 17 years prior to the survey. Sixty-nine percent of respondents held their positions for 0 to 5 years while $41 \%$ held their positions for 5 to 17 years. The mean number of years respondents spent in the position of assistant or associate director was 5.5 years.

Of the responding assistant or associate directors, $78 \%$ worked at research I or II universities, $8 \%$ at doctoral I or II institutions, $6 \%$ at comprehensive universities, $3 \%$ at liberal arts colleges, and $6 \%$ at other settings, such as a state system or national disciplinary faculty development center. The assistant or associate directors held their current positions from 1 to 17 years, with an average of 5.5 years. Interestingly, $69 \%$ of respondents were in their positions as assistant or associate directors for only 0 to 5 years. Most of the assistant or associate directors (85\%) worked full-time in faculty development, while $3 \%$ were employed three-quarters time, $6 \%$ were one-half time, $3 \%$ were onethird time, and $3 \%$ were one-quarter time. Although most were employed full-time in faculty development, $50 \%$ were also teaching faculty, and $14 \%$ served as editors of publications.

\section{RESULTS}

\section{Directors' Quality of Life}

Responding directors reported that they worked from 20 to 120 hours per week' in all their roles, averaging 54 hours per week. In response to questions asking them to rate themselves as excited or bored, enthusiastic or burned out, and growing or stuck, the majority of those who responded to this survey reported that they were excited (94\%), enthusiastic (87\%), and growing professionally $(91 \%) .^{2}$ The majority of directors $(87 \%)$ reported that their other roles (as faculty, editor, assistant or associate dean, assistant or associate provost) energized and refreshed them rather than tired and exhausted them. ${ }^{3}$ There were no significant correlations between age, years as director, or hours worked per week and their excitement and enthusiasm for work.

Although directors were quite positive in their perceptions of their work, they also reported that their work exacted a personal toll. In response to questions regarding stress, many reported various symptoms of stress, including 
headache (43\%), irritability (33\%), and depression (33\%). The most predominate symptom reported was fatigue (77\%). To alleviate stress and to take care of themselves personally, respondents reported a number of strategies, including regular exercise $(74 \%)$, social support $(50 \%)$, and healthier eating habits ( $42 \%)$. When asked how well they handle stress, $64 \%$ reported well or very well, $30 \%$ reported a mixed response, and only $2 \%$ reported handling not well or not well at all. Strategies for caring for oneself professionally and for staying vital included reading professional literature (87\%), attending professional conferences-both disciplinary (73\%) and POD (71\%)-and collaborative work (71\%).

Many of these directors' faculty development centers offer at least some kind of personal support services for faculty. Seventy-one percent of the directors reported that their centers sponsored workshops on personal development topics; $27 \%$ reported that their centers had support groups; $55 \%$ said that their centers had books and articles that promoted personal development.

Frequently the directors' institutions also offered some kind of personal support for faculty as well. Seventy-four percent of directors' institutions offered some kind of health promorion or wellness program; $60 \%$ offered counseling or psychotherapy; $45 \%$ offered infant or preschool childcare; $25 \%$ offered career counseling; $14 \%$ offered employment services for spouses or partners; $5 \%$ offered after-school care for school-aged children.

The primary professional challenge for directors included lack of resources $(51 \%)$, including lack of funding, time, and staff. Thirty-seven percent of the respondents also reported that they were challenged by individual professional issues such as deciding about one's professional future, establishing oneself as an expert in faculty development, having responsibility without authority, keeping up with professional literature, and the like. Twenty-eight percent were challenged by programmatic issues such as engaging faculty in the center's programs, establishing a new center, working with adjunct faculty, keeping programs alive and fresh, and the like. Seven percent were challenged by a lack of administrative support and $4 \%$ were challenged by staffing issues.

Personal challenges for directors included balancing time (27\%), family issues (12\%), and mental and physical health issues (11\%). A majority of directors reported that they are sustained by their work (54\%), particularly by the sense of faculty development being meaningful work/making a difference (28\%), the challenge/change/growth of this type of work (14\%), and their commitment and excitement about the field of teaching and learning (12\%). Directors also reported that they are sustained by their family and friends $(33 \%)$, colleagues (21\%), teaching (14\%), recreation (14\%), and spiritual life (10\%). 
Within five years, $25 \%$ of the directors saw themselves as retiring, and $25 \%$ saw themselves as continuing as director in faculty development. Another $10 \%$ anticipated a move higher into the administration, $7 \%$ planned to return to teaching, and $12 \%$ were unsure what they would be doing professionally in five years.

\section{Assistant or Associate Directors' Quality of Life}

Most assistant or associate directors reported that they were excited (86\%), enthusiastic (86\%), and growing professionally $(81 \%)$ in their work. ${ }^{2}$ In all their roles, assistant or associate directors hours worked from 25 to 100 hours per week $^{4}$, with an average of 51 hours per week. Of those who worked in other roles, such as editor or teacher, most (84\%) reported that the other roles energized and refreshed them. ${ }^{3}$ There were no significant correlations between age, years as assistant or associate director, hours worked per week, and enthusiasm for work.

With regard to handling stress, the majority (64\%) reported that they handled stress well or very well, while 33\% reported a mixed response and $3 \%$ did not respond to this question. Symptoms of stress included fatigue (67\%), lack of concentration and distractibility (47\%), headache (47\%), and insomnia or hypersomnia (43\%).

Strategies for dealing with stress included regular exercise (69\%), healthier eating habits (49\%), and social support (46\%). Strategies for professional self-care included attending POD conferences (89\%), reading professional literature $(86 \%)$, attending disciplinary conferences $(60 \%)$, collaborative work (51\%), and exploring new professional topics (51\%).

Like the directors' centers, the assistant or associate directors' centers offered some personal support services for faculty. Twenty-five percent of the assistant or associate directors reported that their centers sponsored workshops on personal development topics; $11 \%$ reported that their centers had support groups; $14 \%$ said that their centers had books and articles that promoted personal development.

More often, the assistant or associate directors' institutions offered some kind of personal support for faculty. Sixty-four percent of assistant or associate directors' institutions offered some kind of health promotion or wellness program; $53 \%$ offered counseling or psychotherapy; $42 \%$ offered infant or preschool childcare; $31 \%$ offered career counseling; $17 \%$ offered employment services for spouses or partners; $8 \%$ offered after-school care for school-aged children. 
Professional challenges for assistant or associate directors included workload (37\%), professional competency (31\%), and administrative changes (26\%). Personal challenges included family issues (34\%) and balancing time (31\%). Practices that sustained assistant and associate directors included family (43\%), work itself (37\%), outside interests (34\%), spiritual life (31\%), and colleagues $(31 \%)$.

Within the next five years, $34 \%$ of the assistant or associate directors saw themselves in the same position; $20 \%$ saw themselves moving up to a higher position; $17 \%$ saw themselves retired; and $17 \%$ were not sure about future professional plans.

\section{Limitations of THE STUdy}

Determining who was to be included in this sample was problematic in that there is no comprehensive database in the United States that identifies center directors and assistant or associate directors and their gender. To identify potential participants, we used the POD Membership Directory (Professional and Organizational Development Network in Higher Education, 2001) and the titles listed with each member's name. Further, we used the first names of individuals to determine gender. Thus, omissions and errors in the data are inherent in such an imprecise system.

Although there was a high response rate to our questionnaire, the participation in this study was voluntary, and we cannot be certain that the results reflect the quality of life of all directors or assistant or associate directors in faculty development. For example, no assistant or associate directors and only three directors responded that they did not handle stress well. Thus, it is unclear whether nonrespondents handle stress as well as respondents, or whether nonrespondents were not able to handle stress well and therefore chose to not participate in the study.

Additionally, the directors were employed by a variety of Carnegie institution types: research, doctoral, comprehensive, liberal arts, two-year, and other. However, most assistant or associate directors were employed by Carnegie Classification research I and II institutions, and this sampling may affect the generalizability of the results for assistant and associate directors.

\section{Discussion}

Although our sample of assistant or associate directors is small, there are no notable differences detected between them and the directors. All faculty development professionals report that despite multiple stressors, challenges, 
and demands, the work itself is satisfying and rewarding. While there are many implications to be drawn from this study, overall the results suggest three broad themes regarding faculty development work.

\section{Challenges and Stress}

Whether they are full-time or part-time in their positions, faculty development professionals spend a great deal of time working. For many, the work entails multiple roles and expectations. The qualitative data collected in Questions 21 and 22 of the survey confirmed and elaborated upon their responses to earlier questions about the number of hours worked and multiple roles. For example, many respondents had comments similar to these:

- "[My biggest challenge is] balancing multiple roles.

- "Bridging the gap between teaching and administration means doing two jobs."

- "[There are] too many needs, too few resources.

- "[There's] too much work. Too many obligations.

- "My stress levels are due to really doing two $75 \%$ time jobs."

Further, both directors and assistant or associate directors perceive a great deal of stress in their positions. The most common challenges were lack of resources, individual professional challenges, and programmatic challenges. Respondents were very articulate in identifying and conveying the depth of their challenges.

- "[My institution's] culture does not value the scholarship of teaching."

- "[I report to a] dean who doesn't value humanity or good teaching."

- "It's the political battles that exhaust me."

- "The scope of what I can imagine is so much broader than what the institution supports."

- "I'm running out of ideas about what to do. I don't know where to take the center and how to get it there."

Almost all faculty developers reported some physical manifestation of stress, primarily fatigue, headache, lack of concentration, insomnia or hypersomnia, irritability, and depression. Yet they were quite self-aware and adept at alleviating that stress, primarily through exercise, social contacts, and healthier eating 
habits. Many respondents' centers offered some kind of personal development services, such as workshops, support groups, and print resources, indicating that in practice, many faculty developers are concerned about their faculty as persons and not just as teachers.

\section{Meaningful Work}

One of our earliest questions concerned the difference in level of professional satisfaction between those who had worked in faculty development for a short versus a long period of time. We were surprised that, in spite of long work hours and difficult challenges, almost all directors and assistant or associate directors-no matter how long they had been in the field-reported a high level of excitement for, enthusiasm about, and growth in their work. This enthusiasm had a lot to do with opportunities to grow, to make a difference in lives, and to do something they deeply cared about, as articulated in their responses to Question 24.

- "What sustains me is the sense that I'm growing-as a teacher, a colleague, and center coordinator."

- "I have a sense of helping advance values and ideas.

- "The sense that I am needed and have something to contribute."

- "The joy of making a difference, the exhilaration of creative work, and the intellectual stimulation of people that I come into contact with."

- "The feedback that I get that I make a difference really sustains me."

- "I love my work, which is really not work to me!"

\section{Change and Creativity}

Since there is a considerable body of literature about faculty who experience midlife burnout and boredom (e.g., Boice, 1993), we were somewhat surprised that there were no significant correlations between age, years as director, or hours worked per week and faculty developers' excitement and enthusiasm for their work. It is interesting to note that there were approximately the same number of respondents who served as directors for 5 years or less and who served over 11 (and up to 33) years. Thus, in this sample-where directors averaged 53 years of age and assistant or associate directors averaged 47 years of age-we have two very distinct populations: those who are new to the formal role of faculty development center administrator, and those have made a career as a faculty development center administrator. Yet all were 
equally excited and enthusiastic about their work, no matter their age. For the new directors who previously held faculty positions, we might posit that seasoned faculty take faculty development positions for professional renewal, and in essence, as an act of faculty development for themselves. If, as many writers have suggested, the challenges of midlife call for increased self knowledge, creativity, generativity, and commitment (Berquist, Greenberg, \& Klaum 1993; Karpiac, 2000), then it would seem logical that a midlife career move into faculty development would provide such opportunities for challenge and new learning and challenge and for making a difference through service to colleagues and the institution. We might also posit that career faculty developers continue to find great satisfaction in their positions because, in general, they do not feel stuck but find other roles (e.g., teaching faculty, editor, or administrator) to keep vital.

\section{Future Directions}

In addition to the three broad themes outlined above, the data provided by this sample of faculty development professionals is rich with puzzles, contradiction, and nuance. It begs to be more fully understood through in-depth interviews, and is ready for a stratified sampling of institution type to discern differences in the quality of life of faculty development professionals in research, doctoral, comprehensive, and liberal arts institutions.

This first effort at characterizing the quality of life of faculty development professionals yields a portrait of very challenged, but very satisfied, individuals. However, these results contradict our experience with various members of POD. Over the years, we spoke with a number of faculty development professionals who reported that they were unhappy, isolated, and/or in crisiswhich was the original impetus for the study. The fact that this study relied upon voluntary participation makes us suspect the results. Thus, additional studies are needed that employ methods to assure that the target population is adequately sampled.

Determining who was to be included in this sample was problematic in that there is no comprehensive database. Our reliance on the POD Membership Directory certainly missed those center directors and assistant or associate directors who do not belong to POD, and may have missed some who were center directors and assistant or associate directors who do belong to POD if their titles were omitted from the POD Membership Directory. Further, the titles listed may not be accurate descriptions of their true roles. For example, some faculty development centers have faculty members as the titular head while their assistant or associate directors actually perform the same functions 
as the directors of other centers. Additionally, we relied upon the first names of the members to determine gender-a very imprecise method. 5 Future researchers need a more accurate way of identifying faculty development professionals and their gender.

It is interesting to note that approximately two-thirds of the respondents were female, and we were pleased that this proportion paralleled the gender of the entire sample. However, this high percentage calls into question the imbalance of males and females in the profession. Like student development, is faculty development experiencing a feminization of the profession? In the past, did faculty development have more or the same percentage of males in the profession? We need more research to investigate this phenomenon, and to explore the implications for our profession and for academe.

Of special concern to us was the number of work hours per week that directors and assistant or associate directors reported. Over the past 20 years, faculty have perceived that academe-and indeed American society-has increased expectations for faculty, and that faculty do their job at great personal sacrifice (Atkins, Brinko, Butts, Claxton, \& Hubbard, 2001). It appears that faculty development professionals-who often are drawn from faculty ranks-carry these expectations into their new role. Although most of our respondents reported that they handle stress well or very well, many have difficulty balancing the many tasks at work, as well as balancing work with their personal lives. An area that needs further study is the amount of time faculty spend working-actual and perceived - and if academe is encouraging workaholism (Fassel, 1990).

In our sample, the directors were employed by a variety of Carnegie institution types: research, doctoral, comprehensive, liberal arts, two-year, and other. However, most assistant or associate directors were employed by Carnegie Classification research I and II institutions. We speculate that research institutions are larger and more financially able to support a larger staff that includes assistant or associate directors. However, it is the mission of research institutions to focus on research more than teaching. We wonder, then, if research institutions are indeed giving more recognition and support to teaching than they had in the past. We need more studies on research institutions, comparing their past and present support (e.g., financial and human resources) for teaching and learning. Coupled with this effort could be the development of a "rule of thumb" ratio of faculty developers to faculty; this ratio could be used as one measure of comparison among programs.

Another intriguing finding in this study is that within five years, only one-fourth of the directors saw themselves as continuing in their positions as 
director in faculty development. Thus, our profession potentially will have 192 directorship positions open-and possibly more if we consider nonPOD directorships. Some of these positions will be filled by the eight assistant or associate directors who wish to move into higher positions, and some will be filled by new individuals entering into the profession. However, at the least, we may be facing a shortage of faculty development professionals in the next five years; and at the most, we will be experiencing a large turnover in professional expertise. Studies are needed to measure the impact of this sea change on our profession, our professionals, and our service to our faculty clientele.

\section{ENDNOTES}

'It is difficult to believe that anyone would work 80,90 , or 120 hours per week. However, four respondents reported that they worked 80 hours per week, one reported 90 hours, and one reported 120 hours. It is important to note that these are the respondents' perceptions of how much time they spend working each week.

2 Because many respondents marked between the Likert scales' demarcations, we converted these five-point scales into nine-point scales. Those who responded 1-5 on the nine-point scales were considered to be excited, enthusiastic, or growing. Those who responded 6-9 on the scales were considered to be bored, burned out, or stuck.

${ }^{3}$ The five-point Likert scale to measure this response was also converted to a ninepoint scale. Respondents who reported 1-5 on the scale were considered to be energized or refreshed by their other roles; those who responded $6-9$ on the seale were considered to be tired or exhausted by their other roles.

4 One assistant or associate director reported working 100 hours per week. It is important to note that this is the respondent's perception of how much time he/she spends working each week.

SUsing the list of first names in our sample of directors and of assistant or associate directors, we identified those names that are commonly assigned to males and those assigned to females. Approximately $35 \%$ of the directors were male, $63 \%$ were female, and $3 \%$ of the names were ambiguous with regard to gender. Approximately $33 \%$ of the assistant or associate directors were male, $62 \%$ were female, and $6 \%$ of the names were ambiguous with regard to gender. Future researchers also need a database that more accurately identifies gender. 


\section{REFERENCES}

Atkins, S. S., Brinko, K. T., Butts, J. A., Claxton, C. S., \& Hubbard, G. T. (2001). Faculty quality of life. In D. Lieberman \& C. Wehlburg (Eds.), To improve the academy. Vol. 19. Resources for faculty, instructional, and organizational development (pp. 323-345). Bolton, MA: Anker.

Atkins, S. S., \& Hageseth, J. A. (1991). The academic chairperson: Leading faculty is like herding cats. Journal of Staff. Program, and Organizational Development, $X(1)$, 29-35.

Berquist, W. H., Greenberg, E. M., \& Klaum, G. A. (1993). In our fffies: Voices of men and women reinventing their lives. San Francisco, CA: Jossey-Bass.

Boice, R. (1993). Primal origins and later correctives for midcareer disillusionment. In M. J. Finkelstein \& M. W. LaCelle-Peterson (Eds.), New directions for teaching and learning: No. 55. Developing senior faculyy as teachers (pp. 33-41). San Francisco, CA: Jossey-Bass.

Branch, V. (1995). Teaching is "job number one": New faculry at a comprehensive university. Journal of Staff. Program, and Organizational Development, 12(4), 209-218.

Centra, J. A. (1976). Faculty development practices in US colleges and universities. Princeton, NJ: Educational Testing Service.

Fassel, D. (1990). Working ourselves to death: And the rewards of recovery. New York, NY: HarperCollins.

Gaff, J. G. (1975). Toward faculty renewal: Advances in faculty, instructional, and organization development. San Francisco, CA: Jossey Bass.

Graf, D., \& Wheeler, D. (1996). Defining the membership: The POD membership survey. Ames, IA: Professional and Organizational Development Nerwork in Higher Education.

Hageseth, J. A., \& Atkins, S. S. (1988). Assessing faculty quality of life. In J. G. Kurfiss (Ed.), To improve the academy: Vol. 7. Resources for student, faculty, and institutional development (pp. 109-120). Stillwater, OK: New Forums Press.

Hageseth, J. A., \& Atkins, S. S. (1989). Building university community: Where's the staff? Journal of Staff, Program, and Organizational Development, 74), 173-180.

Hubbard, G. T., \& Atkins, S. S. (1995). The professor as a person: The role of faculty well-being in faculty development. Innovative Higher Education, 20,117-128. 
Hubbard, G. T., Atkins, S. S., \& Brinko, K. T. (1998). Holistic faculty development: Supporting personal, professional, and organizational well-being. In M. Kaplan (Ed.), To improve the academy: Vol. 17. Resources for faculty, instructional, and organizational development (pp. 35-49). Stillwater, OK: New Forums Press.

Karpiak, I. (2000). The "second call": Faculty renewal and recommitment at midlife. Quality in Higher Education, Q2), 125-134.

Langley, D. J., O'Connor, T. W., \& Welkener, M. M. (2004). A transformative model for designing professional development activities. In C. M. Wehlburg \& $\mathrm{S}$. Chadwick-Blossey (Eds.), To improve the academy: Vol. 22. Resources for faculty, instructional, and organizational development (pp. 145-155). Bolton, MA: Anker.

Lewis, K. G. (1996). Faculty development in the US: A brief history. International Journal of Academic Development, I(2), 26-33.

Lieberman, D. A., \& Guskin, A. E. (2003). The essential role of faculty development in new higher education models. In C. M. Wehlburg \& S. Chadwick-Blossey (Eds.), To improve the academy: Vol. 21. Resources for faculty instructional, and organizational development (pp. 257-272). Bolton, MA: Anker.

Professional and Organizational Development Network in Higher Education. (2001). Membership directory and networking guide. Miami Beach, FL: Author.

Senge, P. M. (1990). The fifth discipline: The art $\delta$ practice of the learning organization. New York, NY: Currency Doubleday.

Tiberius, R. G. (2002). A brief history of educational development: Implications for reachers and developers. In D. Lieberman \& C. Wehlburg (Eds.), To improve the academy: Vol 20. Resources for faculty, instructional, and organizational development (pp. 20-37). Bolton, MA: Anker.

van der Bogert, V., Brinko, K. T., Atkins, S. S., \& Arnold, E. L. (1990). Transformational faculty development: Integrating the feminine and the masculine. In $\mathrm{L}$. Hilsen (Ed.), To improve the academy: Vol. 9. Resources for student, facultys, and institutional development (pp. 89-98). Stillwater, OK: New Forums Press. 


\section{APPENDIX 6.1 \\ QuALITY OF LIFE SURVEY-Directors}

1) In what year were you born?

2) What is your gender? Male Female

3) What is your highest degree and in what field?

4) In what year did you get your highest degree?

5) In what year did you begin as a practitioner in faculty development?

6) How many years have you been the director of a teaching center (present and past positions)?

7) How many years have you been the assistant or associate director (present and past positions)?

8) Current institution:

$\begin{array}{ll}\text { Public } & \text { Research I, II } \\ \text { Private } & \text { Doctoral I, II } \\ & \text { Comprehensive } \\ & \text { Liberal Arts } \\ & \text { Other: }\end{array}$

9) What is your current appointment as director:

Full-time
3/4 time
$1 / 2$ time
$-1 / 3$ time
$1 / 4$ time

10) In your current position as director of a teaching center, are you: excited bored

$$
\text { L }
$$

enthusiastic

burned out

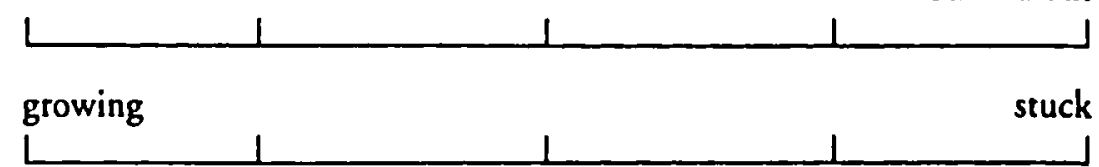


11) What other titles/roles do you currently have:

Qther Role

Faculty/teacher
Ediror
Other:

12) In general, do these other roles:

$\begin{array}{lccr}\text { energize } & \text { refresh } & \text { tire } & \text { exhaust } \\ \text { you } & \text { you } & & \text { you }\end{array}$

13) In general, how many hours per week do you work (in all your roles)?

14) As director of a teaching center (present and past positions), have you ever experienced symptoms of stress?

If yes, please check all that apply:

$\square$ Headache/pain

$\square$ Backache/pain Assistant/associate dean Assistant/associate vice

$\square$ Fatigue

$\square$ Depression

$\square$ Other: $\square$ Gastro-intestinal distress

$\square$ Irritability/anger

$\square$ Insomnia/hypersomnia

$\square$ Anxiety/panic

$\square$ Difficulty concentrating/ distractible

15) What did you/are you doing now to alleviate stress? (Check all that apply.)

$\square$ Psychotherapy

$\square$ Social support

$\square$ Increased drug, smoking, or alcohol consumption

$\square$ Decreased drug, smoking, or alcohol consumption

$\square$ Spiritual activities

$\square$ Medication(s) (name it/them:

$\square$ Other: $\square$ Meditation

$\square$ Healthier eating habits

$\square$ Vitamin supplements

$\square$ Regular exercise

$\square$ Creative activities

16) What other things do you do to care for yourself personally?

17) How well do you feel that you handle stress?
Very well
Well
Mixed
Not well
Not well at all 
18) What do you do to care for yourself professionally, to remain professionally vital? Check all that apply:

$\square$ Read professional literature

$\square$ Attend disciplinary conferences/events

$\square$ Collaborate in teaching, research, etc.

$\square$ Explore new professional topics $\square$ Other: $\square$ Atrend POD conference

$\square$ Attend regional faculty development conferences

$\square$ Attend conrferences/training on teaching/learning

$\square$ Attend conferences/training on technology

19) Does your center offer any personal development programs or services? If yes, check all that apply:

$\square$ Workshops (sample topics):

Support groups

$\square$ Books and articles

Other:

20) Does your institution offer any personal development programs or services?

$\square$ Counseling/psychotherapy (individual or group)

$\square$ Childcare facilities (infant/preschool)

$\square$ After school/holiday program (school-aged)

$\square$ Career counseling

$\square$ Health promotion/wellness program

$\square$ Spouse/partner employment

$\square$ Other:

21) What is the biggest professional challenge that you face right now as center director?

22) What is the biggest personal challenge you face right now?

23) Where do you see yourself five years from now?

24) What sustains you? 